\title{
Experiências no Planejamento da Disciplina Prática do Ensino Médio I
}

\author{
André Augusto Deodato*
}

\section{Resumo}

No curso de Licenciatura em Matemática da Universidade Federal de Ouro Preto, modalidade presencial, estudantes do $4^{\circ}$ período frequentam uma disciplina intitulada Prática do Ensino Médio I. Este relato de experiência tem objetivo de descrever o processo de construção e o desenvolvimento do planejamento da referida disciplina e também de analisar contribuições dessa disciplina tanto para o professor quanto para os licenciandos que a cursaram. O material empírico analisado foi produzido pelo professor durante o desenvolvimento da disciplina. A organização e análise desse material se fundamenta teórico-metodologicamente na Teoria Histórico-Cultural da Atividade. Analisou-se uma situação ocorrida durante o desenvolvimento da disciplina Prática do Ensino Médio I, que ilustra como a relação do planejamento com os tensionamentos do cotidiano pode contribuir para o início de miniciclos expansivos na atividade. Dentre os resultados caracterizados neste relato, destaca-se que foram identificados indícios de processos expansivos na atividade do professor da disciplina e na atividade de um dos licenciandos. Destaca-se ainda que foi possível identificar reverberações das aulas nas produções escritas dos referidos discentes.

Palavras-Chave: Docência no Ensino Superior, Sala de Aula de Matemática, Planejamento, Licenciatura em Matemática, Teoria Histórico-Cultural da Atividade

\footnotetext{
* Doutor em Educação pela Universidade Federal de Minas Gerais. Professor Adjunto do Departamento de Educação Matemática (DEEMA) e Professor Permanente do Programa de Pós-Graduação em Educação Matemática (PPGEDMAT) da Universidade Federal de Ouro Preto, Brasil. E-mail: andre.deodato@ufop.edu.br
}

Recebido em: 09/01/2020 - Aceito em: 28/07/2020.

https://doi.org/10.5335/rbecm.v3i2.10540

http://creativecommons.org/licenses/by-nc-nd/4.0 


\section{Introdução}

O planejamento - entendido como um processo contínuo, identificado na ação docente, processo que é racional, que prevê organização, que vai além das demandas administrativas, que é político e pedagógico - é uma das diferentes tarefas que são demandadas dos docentes (LIBÂNEO, 1994). Foi inspirado por essa concepção, recém-chegado à docência no Ensino Superior, depois de um período de quase 10 anos na Educação Básica, que um professor começou a pensar em como organizar a disciplina Prática do Ensino Médio I.

Inicialmente, o planejamento da mencionada disciplina se forjou a partir: da leitura da ementa da disciplina (portanto, em diálogo com uma dimensão mais pedagógico-administrativa); da adaptação do material já produzido e generosamente socializado pelos professores de departamento; das reminiscências construídas como professor de Matemática, na Educação Básica.

Com o desenvolvimento da disciplina, durante o segundo semestre de 2019, esse planejamento foi alterado, algumas vezes, na medida em que demandas do cotidiano se colocavam. Esse processo de adaptação do planejamento requereu diálogo e negociação tanto com os licenciandos quanto com as próprias concepções do professor. Portanto, no movimento dialético entre teoria e prática, entre o fazer e pensar sobre o fazer (FREIRE, 1996), a disciplina Prática do Ensino Médio I foi se constituindo como espaço de experimentação, para compartilhamento de dúvidas e para reflexão sobre "certezas" já enraizadas, ou em outros termos, para desenvolvimento de uma prática docente crítica (FREIRE, 1996).

Finalizada a disciplina, o professor, motivado pela experiência vivenciada, se propôs a olhar para o material produzido, para sistematizar - e dividir com professores e futuros professores - os erros e acertos, as surpresas e os desafios, enfim, o caminho de aprendizado que ali experienciava. Assim, neste relato de experiência, os objetivos são os seguintes: i) descrever o processo de construção e o desenvolvimento do planejamento da disciplina Prática do Ensino Médio I; ii) descrever e analisar indícios de expansão na atividade em que os licenciandos e o professor foram sujeitos.

Para tanto, o texto está organizado em quatro seções. Nesta primeira, é apresentado o contexto que inspira a escrita do relato e os objetivos que foram eleitos para nele serem perseguidos. Na segunda, é caracterizado o planejamento da disciplina Prática do Ensino Médio I, algumas das adaptações que nele foram realizadas e 
as razões cotidianas que levaram a essas adaptações. Em seguida, na seção três, é exposto um exemplo que ilustra os movimentos de expansão na atividade (ENGESTRÖM E SANNINO, 2010) caracterizada. Nessa mesma seção, são caracterizados os conceitos que fundamentam a análise do exemplo. Em seguida, o relato é finalizado com algumas considerações e com as referências.

\section{O planejamento da disciplina}

No segundo semestre de 2019, foi ministrada para estudantes da licenciatura em Matemática, modalidade presencial, a disciplina Prática do Ensino Médio I, disciplina de 60 horas, com dois encontros semanais de 1h40min. Com essa disciplina, pretendia-se, principalmente que os licenciandos: refletissem sobre a(s) visão (visões) de Matemática evidenciada(s) nos documentos oficiais; conhecessem e ponderassem sobre diferentes estratégias metodológicas utilizadas por professores que ensinam Matemática; elaborassem propostas de ensino e vivenciassem situações de aprendizagem relacionadas com a sala de aula de Matemática do Ensino Médio.

Foi indicado, no planejamento, que a avaliação seria feita, a partir da análise de: assiduidade; pontualidade; engajamento no desenvolvimento das tarefas; participação oral; produção de registros escritos. Cabe destacar que, foram previstos registros escritos em trabalhos individuais (elaboração de uma carta de apresentação, de um plano de aula e de um relatório da observação que seria feita em uma escola) e trabalhos coletivos - envolvendo análise das metodologias Nossa Escola Pesquisa Sua Opinião (NEPSO) e Modelagem Matemática, do Guia 2018 produzido para apresentar os livros de Matemática aprovados no Plano Nacional do Livro Didático (BRASIL, 2017b), da Base Nacional Comum Curricular (BRASIL, 2017a) e da Matriz de Referência do Exame Nacional do Ensino Médio ${ }^{1}$.

As aulas foram organizadas considerando a necessidade de construção da autonomia por parte dos licenciandos. Portanto, foi pensada uma organização em duas etapas, sendo que, na primeira delas, haveria maior centralidade (LAVE E WENGER, 1991) nas ações do professor e, na segunda, a ideia era que as ações dos licenciandos assumissem maior centralidade.

Na primeira etapa, foram preparadas aulas com intenção de propor discussões mais conceituais sobre o ensino de funções. A expectativa do professor era, a partir

1 Disponível em: http://download.inep.gov.br/download/enem/matriz_referencia.pdf. Acesso: 23 jul. 2020. 
de tais discussões, tecer uma rede de situações vivenciadas tanto em sua própria prática - forjada durante quase 10 anos na Educação Básica - quanto na literatura (CARAÇA, 1951; PONTE, 1991; ZUFFI, 2016). Com isso, ele pretendia diminuir a distância entre teoria e prática, na direção de alcançar uma das qualidades, descritas por Paulo Freire, necessárias a todo aquele ou aquela que ensina. Segundo o autor

Esta avaliação crítica da prática vai revelando a necessidade de uma série de virtudes ou qualidades (...) As qualidades ou virtudes são construídas por nós no esforço que impomos para diminuir a distância entre o que dizemos e o que fazemos. (FREIRE, 1996, p.65).

Nessa tessitura estavam previstas tarefas por meio das quais os licenciandos pudessem entender a relação da historicidade (ENGESTRÖM E SANNINO, 2010) com o desenvolvimento do conceito de função e os impactos daquela em alguns documentos oficiais (BRASIL, 1998; 2002; 2017a). A partir daí, a expectativa era que eles refletissem sobre, por exemplo: i) a diferença entre o conceito e a expressão analítica de uma função; ii) as contribuições de diferentes abordagens (algébrica, numérica, geométrica) para a construção do conceito de função e iii) as influências das tecnologias digitais no ensino de funções.

Ainda nessa primeira metade da disciplina, aulas foram preparadas para os discentes conhecerem diversas estratégias metodológicas identificadas nas práticas de professores que ensinam Matemática com a intenção de que eles construíssem e ensinassem a construir "diferentes trajetórias na elaboração do conhecimento" (CAMBRAIA E BENVENUTTI, p.95, 2018). Uma dessas estratégias, intitulada NEPSO, dialogava com a metodologia de projetos. Para apresentá-la foi organizada uma oficina, fundamentada em Lima et al (2010) e aplicada em um trabalho desenvolvido por Deodato e Batista (2013). Uma segunda estratégia planejada, que também seria apresentada por meio de oficina, referenciada em Grando (2000) e Fiorentini e Miorim (1990), envolvia o uso dos jogos e materiais manipulativos no ensino de Matemática.

Em ambos os casos, havia a previsão de, depois das oficinas, reservar um momento para refletir sobre as potencialidades e os limites de cada uma das estratégias e para fazer as delimitações conceituais consideradas necessárias. No caso da reflexão sobre o uso de jogos, por exemplo, a intenção era ponderar sobre, por um lado, algumas expectativas depositadas nos jogos como facilitadores para a aprendizagem de Matemática e, por outro, as críticas que apontavam os jogos como "obstáculos" no 
processo de aprendizagem. Ainda sobre os jogos e materiais manipulativos, a título de ilustração, pareceu relevante compartilhar com os licenciandos as diferenças entre: material manipulativo estático e dinâmico (RODRIGUES, 2011); jogo (HUIZINGA, 1990), jogo matemático (GARDNER, 1961) e jogo pedagógico (MOURA, 1992).

A terceira estratégia, caracterizada no planejamento, envolvia Modelagem Matemática. Para tanto, foi organizado um momento mais teórico que intencionava apresentar aos licenciandos: parte do cenário atual da produção relacionada com Modelagem Matemática na Educação Matemática (BURAK, 1992; BARBOSA, 2001; ARAÚJO, 2002; BASSANEZI, 2002; BIEMBENGUT E HEIN, 2002; FRANCHI, 2007; CALDEIRA, 2009; KLÜBER, 2017; OLIVEIRA E BARBOSA, 2017, ALMEIDA, 2018; entre outros); resultados de pesquisas que relacionam Modelagem Matemática e Formação de Professores (BARBOSA, 2001, 2003; CAMPOS E LUNA, 2011; SILVEIRA E CALDEIRA, 2012; ROSA E KATO, 2014) e aspectos históricos da Modelagem Matemática na Educação Matemática (FIORENTINI, 1994; QUARTIERI E KNIJNIK, 2012).

Assim, levando em consideração a complexidade do conceito de Modelagem Matemática (MM), a expectativa era fazer um recorte, para discutir a dimensão da MM que mais se aproximava da noção de abordagem metodológica. Para tanto, foi preparada uma aula na qual os estudantes foram desafiados a, em grupo, propor uma tarefa envolvendo Modelagem Matemática que pudesse ser desenvolvida em uma sala de aula de Matemática, no Ensino Médio. Nessa tarefa, a intenção era que os licenciandos decidissem sobre o grau de interferência do professor (tarefa mais ou menos "controlada"), pensassem em possíveis soluções para ela (antevendo dificuldades que os estudantes de Ensino Médio poderiam sentir), refletissem sobre a necessidade (ou não) de encontrar um "modelo matemático", para resolver um problema, dentro de uma tarefa de MM.

Durante o trabalho com MM, a ideia era ponderar sobre os limites dessa estratégia e mostrar que ela poderia apresentar fronteiras com outras estratégias metodológicas, como por exemplo a Resolução de Problemas (RP). Depois disso, a expectativa era aproveitar o ensejo para caracterizar a RP como um quarto tipo de estratégia metodológica.

A RP ganharia elementos mais concretos a partir do desenvolvimento de um problema preparado para ser resolvido fazendo uso do GeoGebra². A previsão era 2 Apesar de não ser o primeiro objetivo do planejamento, nele ficou sinalizado que o uso do GeoGebra poderia 
que, munidos da discussão conceitual iniciada quando a MM foi caracterizada e já tendo experimentada uma aula organizada na lógica de uma certa compreensão de $\mathrm{RP}$, os licenciados pudessem ter material teórico e empírico para não só conhecer a metodologia em questão, mas também para diferenciar, por exemplo: exercício de reconhecimento, exercício de algoritmos, problema-padrão, problemas heurísticos, situações-problema e problemas quebra-cabeça (ALEVATTO, 2005).

Nessa primeira fase da disciplina, também estavam planejados trabalhos, que envolviam leitura e análise do Guia PNLD 2018 (BRASIL, 2017b), de parte da Base Nacional Comum Curricular (BRASIL, 2017a), em ambos os casos, com foco no Ensino Médio; e, também, da matriz de referência do Exame Nacional do Ensino Médio.

Estavam ainda previstas aulas teóricas nas quais seriam discutidos com os licenciandos: os problemas da contagem e da medida (CARAÇA, 1951), as ideias da adição e da subtração dos números naturais (CENTURIÓN, 1995) e os diferentes significados dos números racionais (DAVID E FONSECA, 2005).

Na segunda metade da disciplina, a previsão era que os licenciandos se tornassem mais conscientes em relação às potencialidades e aos limites das metodologias que conheceram. Além disso, a expectativa era que ampliassem a visão que tinham em relação à influência dos documentos oficiais nas escolhas metodológicas dos professores e das professoras. Assim, a ideia era dar mais protagonismo a eles de tal forma que se sentissem à vontade para preparar um plano de aula e experimentá-lo durante as aulas da disciplina.

No planejamento, todos os licenciandos receberiam um modelo ${ }^{3}$ de plano de aula. Nesse modelo, os tópicos a serem organizados, estavam separados em duas categorias. Na primeira, intitulada contextualização da aula, os discentes seriam convidados a indicar o tema, o público-alvo e os objetivos da aula; na segunda, intitulada apresentação do conteúdo, esperava-se que apresentassem reflexões sobre o tema (com foco no ensino de Matemática) e sobre a metodologia escolhidos, e, também, um desenvolvimento detalhado da aula. Havia, ainda, um campo no qual era demandado que apresentassem estratégias de avaliação para a aula elaborada e, outro, para indicação das referências no qual era solicitado, especificamente, que

também criar ensejo para fazer uma breve caracterização histórica das fases das tecnologias digitais no Brasil (BORBA, SILVA E GADANIDIS, 2014).

3 Esse modelo foi construído com base no material disponibilizado por um dos professores do departamento e no acervo pessoal do autor do artigo. 
cada licenciando indicasse pelo menos um dos livros didáticos aprovados no PNLD 2018.

Um aspecto que merece destaque é que, cada estudante, na elaboração do plano, poderia escolher um colega da disciplina para ajudá-lo na preparação da aula. Além disso, a proposta previa o seguinte fluxo: os licenciandos elaborariam o plano; ele seria enviado ao professor; seria marcada uma reunião, fora do horário de aula, para discutir as dúvidas surgidas no processo de elaboração e para pensar sobre aspectos que não estivessem claros no plano. Cabe destacar, ainda, que os licenciandos precisariam se organizar para escolher o tema dentro das seguintes temáticas ${ }^{4}$ : Conceito de função, Função afim, Função modular, Função quadrática, Função logarítmica, Função exponencial, Função inversa, Números naturais, Números inteiros, Números racionais, Números irracionais e Números reais.

No planejamento havia, também, a previsão de desenvolvimento de um trabalho de observação em alguma escola de Ensino Médio de Ouro Preto. Todavia, esse trabalho, só ganhou forma durante o desenvolvimento da disciplina e, portanto, será apresentado na subseção seguinte.

\section{Adaptações no planejamento}

Se, de um lado, havia um planejamento que norteava a organização das aulas na disciplina Prática do Ensino Médio I, de outro, também havia o entendimento de que ele não poderia ser inflexível. O professor considerava fundamental adequá-lo aos imperativos do cotidiano e às demandas trazidas pelos discentes. Essa compreensão é harmônica com a de Libâneo (1994), segundo o qual, o planejamento

(...) é uma tarefa docente que inclui tanto a previsão das atividades didáticas em termos de organização e coordenação em face dos objetivos propostos, quanto a sua revisão e adequação no decorrer do processo de ensino (LIBÂNEO, 1994, p.221).

Assim, destacam-se algumas situações não previstas no planejamento inicial bem como as razões que impeliram o professor a inseri-las na disciplina durante $o$ segundo semestre de 2019 . 


\section{O encontro com os educadores indígenas}

A primeira situação não prevista foi o encontro com educadores indígenas. Em agosto de 2019, logo depois do início do semestre letivo, as professoras do curso de Formação Intercultural de Educadores Indígenas (FIEI) da Universidade Federal de Minas Gerais entraram em contato com o professor da disciplina de Prática de Ensino Médio I e informaram que os licenciandos do mencionado curso, da habilitação em Matemática, indígenas das etnias Pataxó, Pataxó Hã Hã Hãe e Xariabá, fariam um trabalho de campo em Ouro Preto; nesse contato, elas se mostraram abertas a um possível trabalho entre as duas universidades.

O trabalho de campo em questão ocorreria no dia da aula da disciplina de Prática do Ensino Médio I. O que fazer: adaptar o planejamento e mudar o plano para aquela aula ou seguir o que havia sido planejado? A questão foi levada para a sala de aula, ponderada com os licenciandos e, coletivamente, optou-se pela adaptação.

Em parceria com o coletivo (professores e licenciandos) do FIEI e com os estudantes da disciplina Prática do Ensino Médio I, foi organizado um evento, na forma de Roda de Conversa que envolveu além dos organizadores, professores de Matemática da Educação Básica e do Ensino Superior, Estudantes de Pós-graduação em Educação Matemática da Universidade Federal de Ouro Preto e bolsistas do FIEI.

Os licenciandos além de ajudar na escolha dos convidados, contribuíram com a elaboração de questões que nortearam a organização da Roda de Conversa. Eles elaboraram questões, sobretudo, relacionadas com o trabalho envolvendo Matemática desenvolvido em escolas do Ensino Médio. Algumas dessas questões seguem, abaixo, na Figura 1. 
Figura 1: Perguntas norteadoras

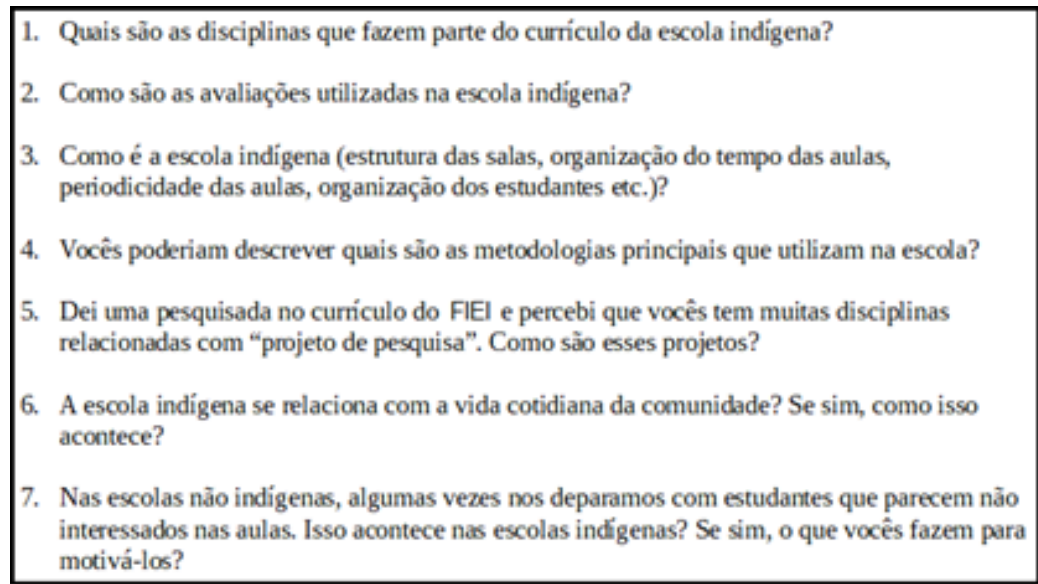

Fonte: autor.

Depois da Roda de Conversa, em função das questões que ali foram abordadas e atendendo à solicitação de alguns licenciandos, foram destinados momentos em algumas aulas para reflexão sobre o que a eles pareceu curioso em relação ao professor de Matemática indígena ou sobre a organização da escola indígena e também sobre as diferenças do currículo da Licenciatura que cursavam e daquela cursada pelos estudantes indígenas da Universidade Federal de Minas Gerais.

\section{O trabalho de observação}

Um aspecto construído no desenvolvimento da disciplina, previsto, em alguma medida, no planejamento inicial, foi o trabalho de observação.

Os licenciandos, em sua maioria, já conheciam escolas de Ensino Fundamental e/ou Médio, seja porque participavam do Programa Institucional de Bolsas de Iniciação à Docência, seja porque já trabalhavam com algum tipo de monitoria. Em muitos casos, tais experiências, considerando os relatos orais e registros escritos produzidos, aparentemente, haviam produzido neles uma impressão negativa em relação às instituições públicas de ensino.

Se, por um lado, o professor da disciplina considerava importante que os estudantes conhecessem a "realidade", em alguns casos perversa (LIBÂNEO, 2012), das escolas públicas brasileiras, por outro, a ele parecia igualmente importante que 
os licenciandos tivessem a oportunidade de vivenciar novas experiências para não generalizar a impressão já construída. Por isso, a instituição de ensino indicada para a realização do trabalho de observação, ainda não caracterizada no planejamento, foi pensada a partir dessa demanda. Fez-se, então, a escolha de uma escola pertencente à rede pública federal, reconhecida na região por ter não só professores com práticas exitosas, mas também por ter alunos egressos, em muitos casos, frequentando boas universidades.

Uma vez escolhida a escola, fez-se um contato inicial com um dos professores que nela ensinava Matemática. Em uma primeira reunião, ocorrida na própria instituição, o trabalho de observação foi apresentado para o professor que não apenas concordou prontamente em receber os licenciandos como também envolveu outros três professores da instituição na realização do mesmo. Cabe destacar que esse professor já tinha o costume de receber estagiários e havia construído uma trajetória de formação na Educação Matemática.

Em seguida, ficou acertado que antes dos licenciandos entrarem em sala de aula, eles, de um lado, na universidade, participariam de algumas aulas para prepará-los para essa inserção. De outro lado, na escola, participariam de um "bate-papo" com o professor para esclarecerem dúvidas sobre o funcionamento da instituição, sobre o percurso formativo do docente e sobre outras questões que pudessem eventualmente surgir.

Assim, o planejamento foi novamente adaptado. Portanto, foram organizadas novas aulas para prepará-los para a inserção na escola. Nessas aulas, foram construídos acordos em relação ao conteúdo e à forma do relatório que os licenciandos deveriam produzir quando terminassem o trabalho de observação. Cada discente pôde escolher qual dos quatro professores da instituição gostaria de acompanhar. Também merece destaque a aula na qual se organizou um trabalho para "treinar o olhar e o ouvir" dos licenciandos com a intenção de qualificar a descrição que seria por eles produzida. Esse trabalho foi feito com base no material desenvolvido por professores do Observatório da Juventude da Faculdade de Educação da Universidade Federal de Minas Gerais ${ }^{5}$. Com auxílio desse material, os licenciandos realizaram tarefas por meio das quais puderam perceber que uma mesma situação pode

5 Esse material foi adaptado do acervo gentilmente cedido por uma professora do Departamento de Ciências Aplicadas à Educação. Ela é integrante do Observatório da Juventude. Maiores informações disponíveis em: http://observatoriodajuventude.ufmg.br/. Acesso em: 23 de jul. 2020. 
ser interpretada de diferentes maneiras, dependendo do foco que é nela colocado ${ }^{6}$ . Assim, a expectativa era que conseguissem produzir um trabalho de observação marcado por uma descrição não superficial. Ainda nessas aulas preparatórias, foram reservados momentos para conversas sobre diferenças nos fluxos de funcionamento de uma escola da Educação Básica (em relação ao de uma universidade) e sobre os cuidados necessários para o estabelecimento de uma relação adequada com os alunos que lá encontrariam.

Depois dessas aulas de preparação, os licenciandos foram apresentados ao professor da escola que os acolheu e os encaminhou aos demais docentes envolvidos no trabalho. Em seguida, eles foram autorizados a iniciar a observação.

\section{As demandas dos licenciandos}

O planejamento também sofreu alterações por influência de demandas trazidas pelos licenciados. Essas demandas ora eram motivadas pela prática daqueles que já atuavam nas escolas, ora por algum fator relacionado com experiências vivenciadas no próprio curso de graduação em Matemática.

Em uma das aulas, realizada ainda na primeira parte da disciplina, um dos estudantes se mostrou muito resistente ao uso de tecnologias digitais nas aulas de Matemática. O argumento utilizado passava pela "falta de controle" que, na opinião dele, deixava o professor muito exposto na sala de aula. Mesmo depois de diversas discussões sobre se "ficar no controle" era de fato necessário para se constituir um "bom professor", o licenciando permaneceu reticente. A despeito disso, ele solicitou que fosse preparada uma aula para maior detalhamento da plataforma de aprendizagem intitulada "Kahoot" , mencionada brevemente durante uma das aulas. A solicitação do aluno, fez com que, mais uma vez o planejamento fosse alterado, com a disciplina em curso.

Em outra situação, esse mesmo discente que estava nos semestres finais da graduação, ao contrário da maioria da turma que cursava o $4 \square$ período, trouxe para disciplina uma dúvida que surgiu quando desenvolvia seu Trabalho de Conclusão

6 Para aprofundar a discussão sobre essa questão, foi também preparada uma tarefa baseada no livro "Zoom" (BANYAI, 1995). Nessa tarefa foram discutidas as diferenças produzidas por uma descrição muito focada no objeto (lente em zoom in) e outra muito focada no contexto no qual o referido objeto está inserido (lente em zoom out).

7 Kahoot é uma plataforma de aprendizagem baseada em jogos. Maiores informações disponíveis em: https:// kahoot.com/. Acesso em 23 jul. 2020. 
de Curso (TCC). No TCC, ele pretendia analisar tarefas envolvendo Modelagem Matemática que desenvolveria em uma escola pública de Ouro Preto.

Em uma das tarefas que o licenciando já havia desenvolvido, ele se deparou com estudantes que, diante de um problema resolvido a partir da divisão de dois inteiros com resultado decimal, acabaram respondendo equivocadamente ao que era perguntado, porém, deixando registros de que haviam feito as contas corretamente. Ele se apoiou nas discussões que estavam sendo feitas na disciplina de Prática do Ensino Médio I, sobre evitar avaliações binárias, para perguntar: "nesse caso, devo considerar que os alunos estão certos ou errados?". Essa questão levou à reflexão de que, a decisão caberia ao professor, mas que, mais importante que pensar se estava certa ou errada, essa questão evidenciava que alguns alunos precisavam ampliar o entendimento que tinham sobre os significados da divisão; o "erro", talvez, estivesse relacionado com um ensino muito focado no entendimento dos procedimentos.

Em ambos os casos, demandas trazidas por um licenciando, mudaram o curso de aulas que já haviam sido planejadas.

\section{Os atendimentos individualizados}

Outro aspecto que requereu ajuste no planejamento foram os atendimentos individualizados para discussão do plano de aula. Como destacado no início da seção 2, o fluxo previsto era o seguinte: os licenciandos elaborariam o plano; eles o enviariam ao professor; seria marcada uma reunião, fora do horário de aula, para discutir as dúvidas surgidas no processo de elaboração do plano e para ponderar sobre aspectos dele que não estivessem claros.

Nesse fluxo, a previsão era que o plano de aula fosse enviado com antecedência, para que, no momento do atendimento individualizado, ele já tivesse sido lido pelo professor; além disso, essa antecedência contribuiria para a produção de sugestões sobre o que poderia ser melhorado para o desenvolvimento da aula. Em alguns casos, o fluxo atendeu ao planejamento. Em outros, a preparação do plano de aula tomou uma centralidade nos encontros. Por exemplo, em alguns casos, tornou-se necessário, mesmo o professor já tendo feito isso em sala de aula, reexplicar os significados dos campos do plano de aula, em outros, foi preciso ajudar os licenciandos a pesquisar sobre se existiam (ou não) materiais didáticos produzidos para dar suporte ao desenvolvimento da aula que eles haviam organizado. 
Outro ponto que demandou ajuste no planejamento foi a organização das aulas que seriam dadas pelos discentes a partir do plano de aula por eles construído. A expectativa era organizar um tempo para os licenciandos desenvolverem a aula e outro momento para os demais discentes e o professor pontuarem sobre as potencialidades e limites identificados. Para as aulas que apostaram em uma organização mais expositiva, essa divisão funcionou bem. Contudo, diversos alunos optaram por desenvolver aulas fazendo uso das metodologias apresentadas na disciplina (Modelagem, Resolução de Problemas, Uso de Jogos e Uso de TICs) e até fizeram uso da História da Matemática como estratégia metodológica, estratégia essa não discutida anteriormente. Em alguns desses casos, as aulas duraram mais tempo que o previsto e o espaço para discussão ficou encurtado, em outras, ao contrário, as aulas terminaram antes do esperado e o tempo para discussão ficou alongado. Essa não previsibilidade, provocou, cotidianamente, ajustes no planejamento de modo que fossem privilegiadas as melhores condições para cada licenciando desenvolver a aula planejada.

\section{A análise de uma situação ilustrativa}

Anteriormente, foram descritos o processo de construção do planejamento da disciplina Prática do Ensino Médio I e o desenvolvimento do referido planejamento por meio da caracterização das adaptações que nele foram realizadas. Agora, pois, será analisada uma situação vivenciada durante o desenvolvimento da referida disciplina, com a intenção de mostrar que nesse percurso de construção e adaptação do planejamento foram identificados indícios de expansões na atividade (ENGESTRÖM E SANNINO, 2010) que tinha os licenciandos e o professor como sujeitos.

\section{Referencial teórico-metodológico}

Para que a análise desejada seja empreendida, torna-se necessário fazer referência, ainda que brevemente, a alguns conceitos da Teoria Histórico-Cultural da Atividade (THCA), isso porque a mesma será fundamentada nesse referencial teórico. Como as apropriações dessa teoria são as mais diversas possíveis, considera-se relevante destacar que, neste relato, serão utilizadas como inspiração aquelas identificadas em David e Tomaz (2015) e em Engeström e Sannino (2010) - respec- 
tivamente pesquisadoras e pesquisadores membros dos grupos intitulados "Teoria da Atividade Histórico-Cultural na pesquisa em Educação" e "Center for Research on Activity, Development and Learning" .

Considera-se, em concordância com os autores antes mencionados, que a atividade é a unidade de análise dos fenômenos investigados. Nela, a estrutura básica, ancorada nos trabalhos de Vigotski, possibilita a análise da relação entre o sujeito e seu objeto de desejo, mediada pelos artefatos. Já a estrutura ampliada, complementada pelos trabalhos de Engeström, conta com uma base social na qual estão as regras, a comunidade e a divisão de trabalho. Para este relato é relevante explicar que o componente comunidade permite a identificação dos atores que participam da atividade e o componente regras possibilita a identificação dos combinados, explícitos ou não, que são estabelecidos na atividade.

Essa delimitação de unidade de análise, proposta pela THCA, não só oferece uma forma de organizar o material empírico, mas também permite o uso de ferramentas conceituais da teoria para empreender a análise. Contudo, a THCA demanda auxílio de outra lente teórica para colaborar na caracterização de determinados detalhes de processos relacionados com a aprendizagem.

Para atender a essa demanda, seguindo o caminho de Engeström e Sannino (2010), o presente trabalho se apoiará na ideia de Aprendizagem Expansiva. Segundo os referidos pesquisadores, esse tipo de aprendizagem é raro e ocorre, quando os sujeitos se deparam com contradições - desdobramentos de tensões historicamente acumuladas - da atividade e procuram alternativas para enfrentá-las. Quando isso ocorre, diz-se que houve um ciclo expansivo de aprendizagem. Todo ciclo é formado a partir de miniciclos. Se os primeiros não são detectáveis, em geral, em períodos curtos de tempo, os últimos, podem ser identificados, inclusive, em situações cotidianas, como por exemplo, aquelas ocorridas durante as aulas de Matemática.

É com essa compreensão que, no presente relato, os conceitos acima mencionados serão utilizados para caracterizar indícios de miniciclos potencialmente expansivos de aprendizagem na atividade em que o professor e os licenciandos foram sujeitos. Mais especificamente, no processo de planejar e adaptar o planejamento, desenvolvido ao longo da disciplina Prática do Ensino Médio I, como descrito nas seções anteriores, professor e licenciandos, foram se tornando sujeitos da atividade

8 O primeiro grupo é sediado na Faculdade de Educação da Universidade Federal de Minas Gerais, em Belo Horizonte; o segundo, na Universidade de Helsinque, na cidade homônima. Ambos possuem membros de diferentes áreas do conhecimento (Educação, Engenharia, Arquitetura, etc.). 
(ENGESTRÖM E SANNINO, 2010) na medida em que se apropriavam (SMOLKA, 2000) dos artefatos produzidos (metodologias, discussões, vivências, etc.) na busca pelo objeto coletivo ali partilhado (desenvolvimento da prática docente). Nesse percurso, foram identificados diferentes indícios de processos expansivos, alguns dos quais, serão apresentados a seguir.

\section{Uma aula de função a partir da música Bat Macumba}

No plano de aula, preparado por um dos licenciandos, ele pretendia trabalhar a ideia de que a função era um tipo especial de relação. Dentro desse plano, em uma das etapas, separou os colegas de disciplina, em grupos, entregou a letra de uma música intitulada Bat Macumba , reproduziu-a na sala de aula, entregou um roteiro (Figura 2), fez algumas explicações e deixou os grupos trabalharem.

Figura 2: Perguntas norteadoras

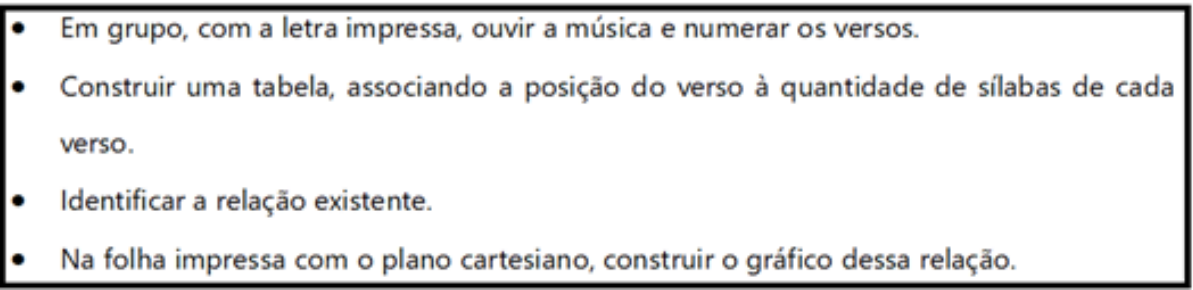

Depois que todos terminaram, ele discutiu as estratégias apresentadas pelos grupos e, a partir daí, caracterizou o conceito de função quando domínio e imagem pertencem ao conjunto dos números naturais.

Destacam-se, nesse caso, duas situações que parecem indícios de processos expansivos de aprendizagem. A primeira delas é que o discente pareceu se apropriar de um artefato que a ele foi apresentado na disciplina (estratégia metodológica) para ampliar os recursos utilizados em sua prática, na preparação da aula. Essa apropriação não ocorreu sem tensionamento. Durante a preparação do plano de aula, o discente queria experimentar a tarefa de modelagem, mas queria também fazer uso de recursos mais ortodoxos (por exemplo, apresentar o conceito de função a partir do uso de diagrama, antes da tarefa). Nas reuniões individuais entre ele e o professor foi discutida a adequação (ou não) de se fazer uso desse recurso mais 
ortodoxo numa tarefa como a que ele estava a propor. Depois de um processo de negociação, ele preferiu apostar no desenvolvimento da tarefa sem fazer uso do diagrama. Ao se apropriar desse artefato, o discente, sujeito da atividade, tensionado pela comunidade na qual estava inserido, enfrentou a tensão e evidenciou um indício de miniciclo expansivo de aprendizagem.

A segunda é que, quando essa tarefa foi discutida, ainda nas reuniões individualizadas, em um primeiro momento, o professor ficou reticente sobre a adequação da proposta trazida pelo licenciando. Inicialmente considerou que seria uma tarefa aberta demais e, dadas as condições, parecia haver risco de ele não conseguir desenvolver seu plano. Todavia, ao refletir com mais cuidado sobre a tarefa, ao experimentar solucioná-la e ao ponderar sobre o caminho que vinha propondo na disciplina - o de fazer da sala de aula, na universidade, um lugar de experimentação - foi impelido a aceitar a proposta do licenciando. A questão é que, ao ceder a centralidade que, como professor da disciplina ocupava na atividade - contribuindo assim para a diminuição da assimetria de poder identificada na relação entre professor-aluno -, um novo cenário se constituiu. Nele, não só o discente era convidado a aceitar o não controle como possibilidade, mas o professor da disciplina também. Uma nova regra, pois, se fez notar: professor e licenciandos poderiam, horizontalmente, aceitar a imprevisibilidade como possibilidade educativa.

Com a lente da THCA, olhando para essa segunda situação, considera-se que, por um lado se configurou uma tensão entre sujeito e regras da atividade. Por outro, a flexibilização das regras - sinal de enfrentamento da tensão - pode ter contribuído para o início de um miniciclo expansivo de aprendizagem.

Em outros termos, de um lado, o professor da disciplina e seus pressupostos, divididos com os discentes durante a disciplina, considerando o risco como possibilidade educativa; de outro, o mesmo professor lidando com os ecos de uma comunidade (academia, professores de Matemática com visão mais ortodoxa, etc.) que demandava dele "controle da situação". E foi, por fim, ao enfrentar esse tensionamento que se flagrou um indício de miniciclo expansivo. Uma síntese das duas situações que compõe esse caso está registrada no Quadro 1, apresentado abaixo. 
Quadro 1: Síntese do Sistema de Atividade

\begin{tabular}{|l|l|}
\hline \multicolumn{1}{|c|}{ Atividade 1 } & \multicolumn{1}{c|}{ Atividade 2 } \\
\hline Sujeito: licenciando & Sujeito: professor da disciplina \\
\hline $\begin{array}{l}\text { Artefato: livros consultados, concepções e no- } \\
\text { vas estratégias metodológicas }\end{array}$ & $\begin{array}{l}\text { Artefato: livros consultados, concepções e deba- } \\
\text { tes produzidos na disciplina }\end{array}$ \\
\hline Objeto: desenvolvimento da prática docente & Objeto: desenvolvimento da prática docente \\
\hline $\begin{array}{l}\text { Regra: assumir o protagonismo no desenvolvi- } \\
\text { mento de uma aula de funções }\end{array}$ & $\begin{array}{l}\text { Regra: assumir a centralidade na organização } \\
\text { da aula }\end{array}$ \\
\hline $\begin{array}{l}\text { Comunidade: licenciandos, professor da discipli- } \\
\text { na e professores do departamento }\end{array}$ & $\begin{array}{l}\text { Comunidade: licenciandos e professores do } \\
\text { departamento }\end{array}$ \\
\hline $\begin{array}{l}\text { Divisão de Trabalho: professor da disciplina } \\
\text { valida (ou não) o plano de aula; licenciandos } \\
\text { preparam um plano de aula e assumem o prota- } \\
\text { gonismo no desenvolvimento da aula planejada }\end{array}$ & $\begin{array}{l}\text { Divisão de Trabalho: professor da disciplina } \\
\text { valida (ou não) o plano de aula; licenciandos } \\
\text { preparam um plano de aula e assumem o prota- } \\
\text { gonismo no desenvolvimento da aula planejada }\end{array}$ \\
\hline $\begin{array}{l}\text { Tensão Identificada: fazer uso de uma nova me- } \\
\text { todologia x ceder a recomendações de formas } \\
\text { tradicionais de ensino }\end{array}$ & $\begin{array}{l}\text { Tensão Identificada: assumir os pressupostos } \\
\text { sobre “arriscar" x garantir a manutenção do } \\
\text { controle }\end{array}$ \\
\hline
\end{tabular}

Fonte: Autor.

\section{Considerações finais}

Este relato de experiência foi organizado com os seguintes objetivos: i) descrever o processo de construção e o processo de desenvolvimento do planejamento da disciplina Prática de Ensino Médio I e ii) analisar contribuições dessa disciplina tanto para o professor quanto para os licenciandos que a cursaram. Para descrever a construção, apresentou-se o planejamento a partir da caracterização, dentre outros, dos objetivos da disciplina, dos processos avaliativos e das escolhas teórico-metodológicas do professor. Já para descrever o desenvolvimento, discorreu-se sobre as adaptações impostas pelo cotidiano. Para cumprir o segundo objetivo, analisou-se uma situação envolvendo Modelagem Matemática e a música Bat Macumba. Essa situação revelou que a relação do planejamento com os tensionamentos do cotidiano contribuiu para o início de miniciclos expansivos de aprendizagem. Além do atendimento a esses objetivos anunciados, as vivências comunicadas neste texto também permitem algumas considerações, com as quais ele é finalizado.

A primeira delas é que se considera acertada a escolha de uma escola pública federal para a realização do trabalho de observação dos estudantes. Ao conhecerem a referida instituição, cuja realidade evidenciava experiências exitosas, os licen- 
ciandos se sentiram mais seguros - o que se evidenciou nas falas e nos registros escritos que produziram. Essa escolha foi inspirada sobretudo na crítica que Libâneo (2012) faz ao Estado brasileiro que tem, em muitos casos, produzido políticas que contribuem para a construção de "escolas do conhecimento" para os ricos e "escolas do acolhimento" para os pobres. No trabalho que os licenciandos desenvolveram, puderam identificar um tipo de instituição que acolhe os estudantes sem prescindir de compartilhar o conhecimento historicamente acumulado e socialmente valorizado.

A segunda é que, como professor que preparava a disciplina pela primeira vez, desafiado pela necessidade de produzir um material que não possuía no próprio acervo, o docente da disciplina de Prática do Ensino Médio I precisou equilibrar suas escolhas na elaboração desse material, com o tempo disponível. Esse equilíbrio desejado, se mostrou um desafio que foi algumas vezes superado e, em outras, apenas "contornado". Por exemplo, as aulas teóricas planejadas para o início da disciplina, possibilitaram diversos momentos de discussão e reflexão, seja aquelas sobre função, seja aquelas sobre as diferentes estratégias metodológicas; já as aulas planejadas para o fim da disciplina, sobretudo aquelas dedicadas aos números, acabaram sendo menos exploradas, limitadas pelo tempo, em razão dos ajustes no planejamento, ajustes esses demandados pelas questões descritas, que emergiam do cotidiano.

Outra consideração, a terceira, ilumina reverberações (ou não) das aulas nas produções escritas dos licenciandos. De um lado, os relatórios produzidos por alguns deles, no trabalho de observação evidenciaram que as aulas preparatórias - seja aquelas com tarefas para treinar o olhar e o ouvir, seja os atendimentos individualizados para ajudar na construção do relatório - contribuíram, em alguma medida, para a produção de uma descrição qualificada das aulas observadas na escola. De outro lado, em quase todos os planos de aula, os licenciandos optaram por indicar, como referência, um livro didático reconhecido pela apresentação do conteúdo de modo bastante tradicional, mesmo aqueles que descreviam, em seus planos, aulas envolvendo alguma das "novas" metodologias caracterizadas na disciplina. Quando questionados sobre isso, em geral, sinalizaram concordância com a organização do livro ou dificuldade para acessar a outros livros didáticos nas bibliotecas (das escolas e da universidade) a que tiveram acesso.

Considera-se, por fim, que na disciplina cujo planejamento foi descrito neste relato, foram identificados indícios de processos expansivos, envolvendo os sujeitos 
da atividade, além daqueles evidenciados no exemplo que foi analisado no texto. Destaca-se que esses indícios expansivos foram notados cotidianamente, nas falas e nas posturas, nos posicionamentos nos debates, nos consensos construídos sobre a não oposição entre construir uma boa relação com alunos, a partir de alguns limites, e o querer bem aos educandos; ou ainda, na superação de pressupostos que antes opunham rigor metódico ao acolhimento dos saberes dos educandos. Foi, no processo de desenvolvimento do que havia sido planejado, que licenciandos e professor da disciplina, se fizeram professores mais autônomos (FREIRE, 1996) e mais preocupados com a autonomia dos educandos que passaram e que ainda vão passar por suas vidas.

\section{Experiences in the Planning a Discipline High School Practice I}

\section{Abstract}

In the course of Mathematics Teaching in the Federal University of Ouro Preto, present modality, students of the 4 th semester attend a course entitled High School Practice I. This experience report aims to describe the construction process and the development of the planning of the referred one and to analyze contributions of this discipline to both the teacher and the undergraduate. The empirical material analyzed was produced by the teacher during the course development. The organization and analysis of this material is based theoretically and methodologically on the Cultural-Historical Activity Theory. We analyzed a situation that occurred during the development of the High School Practice I discipline, which illustrates how the relationship between planning and everyday challenges can contribute to the start of expansive minicycles in the activity. Among the results characterized in this report, it is highlighted that evidence of expansive processes was identified in the activity of the professor of the discipline and in the activity of one of the undergraduate students. It is also highlighted that it was possible to identify reverberations of the classes in the written productions of the mentioned students.

Keywords: Teaching in Higher Education, Mathematics Classroom, Planning, Mathematics Degree, Cultural-Historical Activity Theory

\section{Referências}

ALLEVATO, Norma Suely Gomes. Associando o computador à resolução de problemas fechados: análise de uma experiência. Rio Claro: UNESP, 2005. Tese de Doutorado, Instituto de Geociências e Ciências Exatas, Universidade Estadual Paulista, 2005. Disponível em: http:// hdl.handle.net/11449/102164. Acesso em: 23 jul. 2020. 
ALMEIDA, Loudes Maria Werle de. Considerations on the use of mathematics in modeling activities. ZDM - The International Journal on Mathematics Education, v.50, n.1-2, p. 19-30, abr. 2018.

ARAÚJO, Jussara de Loiola. Cálculo, tecnologias e modelagem matemática: as discussões dos alunos. Rio Claro: UNESP, 2002. Tese de Doutorado, Instituto de Geociências e Ciências Exatas, Universidade Estadual Paulista, 2002. Disponível em: http://150.164.25.15/ jussara/ tese/tese.pdf. Acesso em: 10 jan. 2020.

BANYAI, Istvan. Zoom. Tradução de Gilda Aquino. São Paulo: Brinque Book, 1995. 64p.

BARBOSA, Jonei Cerqueira. Modelagem Matemática na sala de aula. Perspectiva, v. 27, n. 98, p.65-74, 2003. Disponível em: http://www.uricer.edu.br/rperspectiva/inicio.php?id_numero=26\#06. Acesso em: 12 nov. 2014

. Modelagem na Educação Matemática: contribuições para o debate teórico. Reunião anual da ANPED, v. 24, n. 7, p. 1-15, 2001. Disponível em: http://www.ufrgs.br/ espmat/disciplinas/funcoes_modelagem/modulo_I/modelagem_barbosa.pdf. Acesso em: 23 jul. 2020.

BASSANEZI, Rodney Carlos. Ensino-aprendizagem com modelagem matemática. São Paulo: Editora Contexto, 2002.

BIEMBENGUT, Maria Salett; HEIN, Nelson. Modelagem matemática no ensino. São Paulo: Editora Contexto, 2002.

BORBA, Marcelo de Carvalho; SILVA, Ricardo Scucuglia Rodrigues da; GADANIDIS, George. Fases das Tecnologias Digitais em Educação Matemática: sala de aula e internet em movimento. Belo Horizonte: Autêntica, 2016.

BRASIL. Ministério da Educação e Cultura - PCN+ Ensino Médio, Orientações Educacionais Complementares aos Parâmetros Curriculares Nacionais, 2002.

Ministério da Educação. Base Nacional Comum Curricular: Fundamentos Pedagógicos e Estrutura Geral da BNCC. Brasília, Distrito Federal, 2017a. Disponível em: http:// basenacionalcomum.mec.gov.br/. Acesso em: 23 jul. 2020.

. Ministério da Educação. PNLD 2018: matemática - guia de livros didáticos - Ensino Médio/ Ministério da Educação - Secretária de Educação Básica - SEB - Fundo Nacional de Desenvolvimento da Educação. Brasília, DF: Ministério da Educação, Secretária de Educação Básica, 2017b. Disponível em: http://www.fnde.gov.br/pnld-2018/\#. Acesso em: 23 jul. 2020.

. Ministério da Educação. Parâmetros Curriculares Nacionais: Terceiro e quarto ciclos do Ensino Fundamental - Matemática. Brasília, DF, 1998. Disponível em: http://portal.mec.gov. br/seb/arquivos/pdf/matematica.pdf. Acesso em: 23 jul. 2020.

BURAK, Dionísio. Modelagem Matemática: ações e interações no processo de ensino-aprendizagem. Campinas: UNICAMP, 1992. Tese de Doutorado, Faculdade de Educação, Universidade Estadual de Campinas, 1992. Disponível em: http://repositorio.unicamp.br/jspui/handle/REPOSIP/252996. Acesso em: 23 jul. 2020.

CALDEIRA, Ademir Donizeti. Modelagem Matemática: um outro olhar. Alexandria, v. 2, p. 33-54, 2009. Disponível em: https://periodicos.ufsc.br/index.php/alexandria/article/view/37940. Acesso em: 23 jul. 2020.

CAMBRAIA, Adão Caron; BENVENUTTI, Leonardo Matheus Pagani. Metodologias ativas e tecnologias digitais na formação do professor de computação. Revista Brasileira de Ensino 
de Ciências e Matemática, v. 1, n.1, p.85-p.98, 2018. Disponível em: http://seer.upf.br/index. php/rbecm/article/view/8476. Acesso em: 23 jul. 2020.

CAMPOS, Ilaine Silva; LUNA, Ana Virgínia de Almeida. Modelagem Matemática, professores e desenvolvimento profissional: possibilidades geradas pela colaboração. In: XIII Conferência Interamericana de Educação Matemática, 2011, Recife. XIII CIAEM, 2011. p. 1-10.

CARAÇA, Bento de Jesus. Conceitos Fundamentais da Matemática. Portugal: Lisboa Editora, 1951.

CENTURIÓN, Marília. Conteúdo e Metodologia da Matemática: números e operações. São Paulo: Editora Scipione, 1995.

DAVID, Maria Manuela Martins Soares; FONSECA, Maria da Conceição Fonseca Reis. Sobre o conceito de número racional e a representação fracionária. Presença Pedagógica, p. 59-71, 2005.

DAVID, Maria Manuela; TOMAZ, Vanessa Sena. Aprendizagens Expansivas Reveladas pela Pesquisa sobre a Atividade Matemática na Sala de Aula. BOLEMA: Boletim de Educação Matemática (Online) , v. 29, p. 1287-1308, 2015. Disponível em: http://dx.doi.org/10.1590/ 1980-4415v29n53a24. Acesso em: 23 jul. 2020.

DEODATO, André Augusto; FARIA, Juliana Batista. Pesquisa sobre Namoro entre Estudantes Brasileiros e Chilenos: A Metodologia 'Nossa Escola Pesquisa sua Opinião' na Sala de Aula de Matemática. In: XI Encontro Nacional de Educação Matemática, 2013, Curitiba. Anais do XI ENEM. Guarapuava: Sociedade Brasileira de Educação Matemática - Regional Paraná, 2013.

ENGESTRÖM, Yrjö.; SANNINO, Annalisa. Studies of expansive learning: Foundations, findings and future challenges. Educational research review, 2010, 5.1: 1-24.

FIORENTINI, Dario. Rumos da pesquisa brasileira em educação matemática: o caso da produção científica em cursos de Pós-Graduação. Campinas: UNICAMP, 1994. Tese de Doutorado, Faculdade de Educação, Universidade Estadual de Campinas, 1994. Disponível em: http:// repositorio.unicamp.br/jspui/handle/REPOSIP/253750. Acesso em: 23 jul. 2020.

FIORENTINI, Dario; MIORIM, Maria Ângela. Uma reflexão sobre o uso de materiais concretos e jogos no Ensino da Matemática. Boletim da SBEM-SP, v. 4, n. 7, 1990. Disponível em: http:// www.pucrs.br/ciencias/viali/tic_literatura/jogos/Fiorentini_Miorin.pdf. Acesso em: 23 de jul. 2020.

FRANCHI, Regina Helena de Oliveira Lino. Ambientes de aprendizagem fundamentados na Modelagem Matemática e na Informática como possibilidades para a Educação Matemática. In: BARBOSA, Jonei Cerqueira; CALDEIRA, Ademir Donizeti; ARAÚJO, Jussara de Loiola (Org.). Modelagem Matemática na Educação Matemática Brasileira: pesquisas e práticas educacionais. 1ed. Recife: Sociedade Brasileira de Educação Matemática SBEM, 2007.

FREIRE, Paulo. Pedagogia da autonomia: saberes necessários à prática educativa (Coleção Leitura). São Paulo: Paz e Terra, 1996.

GARDNER, Martin. Divertimentos Matemáticos. Tradução Bruno Mazza. São Paulo: Ibrasa, 1961.

GRANDO, Regina Célia. O conhecimento matemático e o uso de jogos na sala de aula. Campinas: UNICAMP, 2000. Tese de Doutorado, Faculdade de Educação, Universidade Estadual de Campinas, 2000. Disponível em: http://www.repositorio.unicamp.br/handle/REPOSIP/251334. Acesso em: 23 jul. 2020. 
HUIZINGA, Johan. Homo Ludens: o jogo como elemento da cultura. Tradução João Paulo Monteiro. São Paulo: Perspectiva, 1990.

KLÜBER, Tiago Emanuel. Formação de professores em Modelagem Matemática na Educação Matemática: questões emergentes. Educere et Educare (versão eletrônica), v. 12, p. 1-11, 2017. Disponível em: http://e-revista.unioeste.br/index.php/educereeteducare/article/view/15281/11254. Acesso em: 23 jul. 2020.

LAVE, Jean; WENGER, Ettiene. Situated learning: Legitimate peripheral participation. Cambridge university press, 1991.

LIBÂNEO, José Carlos. Didática. São Paulo: Cortez, 1994.

O dualismo perverso da escola pública brasileira: escola do conhecimento para os ricos, escola do acolhimento social para os pobres. Educação e Pesquisa, v.38, n.1, pp13-28, 2012. Disponível em: http://dx.doi.org/10.1590/S1517-97022011005000001. Acesso em: 23 jul. 2020.

LIMA, Ana Lúcia D’Império et al. Nossa escola pesquisa sua opinião: Manual do professor. São Paulo: Global, 2010. Disponível em: http://www.nepso.net/publicacao. Acesso em: 23 jul. 2020.

MOURA, Manoel Oriosvaldo de. O jogo e a construção do conhecimento matemático. São Paulo, 1992.

OLIVEIRA, Andreia Maria de; BARBOSA, Jonei Cerqueira. Mathematical Modelling in Pedagogic Practices: How teachers deal witch tensions in discourses. Revista Internacional de Pesquisa em Educação Matemática (RIPEM), v. 7, p. 45-60, 2017.

PONTE, João Pedro da. O conceito de função no currículo da Matemática. Educação e Matemática. $\mathrm{n}^{\mathrm{0}}$ 15, 1990.

QUARTIERI, Marli Teresinha; KNIJNIK, Gelsa. Modelagem matemática na escola básica: surgimento e consolidação. Revista Caderno Pedagógico, v. 9, n.1, 2012. Disponível em: http:// www.univates.br/revistas/index.php/cadped/article/view/842. Acesso em: 23 jul. 2020.

RODRIGUES, Fredy Coelho. Laboratório de educação matemática: descobrindo as potencialidades do seu uso em um curso de formação de professores. Belo Horizonte: PUC-MG, 2011. Dissertação de Mestrado, Pontifícia Universidade Católica de Minas Gerais. Disponível em: http://www.biblioteca.pucminas.br/teses/EnCiMat_RodriguesFC_1.pdf. Acesso em: 23 jul. 2020.

ROSA, Cláudia Carreira da; KATO, Lilian Akemi. A Modelagem Matemática e o Exercício do Professor Reflexivo: a experiência de Elias. Perspectivas da Educação Matemática, 2014, 7.14. Disponível em: https://periodicos.ufms.br/index.php/pedmat/article/view/881. Acesso em: 23 jul. 2020.

SILVEIRA, Everaldo; CALDEIRA, Ademir Dionísio. Modelagem na sala de aula: resistências e obstáculos. Boletim de Educação Matemática, v. 26, n. 43, 2012. Disponível em: http://dx.doi. org/10.1590/S0103-636X2012000300012. Acesso em: 23 jul. 2020.

SMOLKA, Ana Luiza Bustamente. O (im)próprio e o (im)pertinente na apropriação das práticas sociais. Cadernos Cedes. Ano XX, n. 50, p. 26-40, abril, 2000. Disponível em: http://dx.doi. org/10.1590/S0101-32622000000100003. Acesso em: 23 de jul. 2020.

ZUFFI, Edna Maura. Alguns aspectos do desenvolvimento histórico do conceito de função. HIPÁTIA-Revista Brasileira de História, Educação e Matemática, v.1, n.1, pp 1-10, 2016. Disponível em: https://ojs.ifsp.edu.br/index.php/hipatia/article/view/436. Acesso em: 23 de jul. 2020. 